\title{
Enhanced evaluation of a Lagrangian-particle air pollution model based on a Šaleška region field data set
}

\author{
B. Grašič, P. Mlakar, M. Z. Božnar \& G. Tinarelli \\ MEIS d.o.o., Mali Vrh pri Šmarju 78, 1293 Šmarje-Sap, Slovenia \\ ARIANET s.r.l., Via Gilino 9, 20128 Milano, Italy
}

\begin{abstract}
Lagrangian-particle air pollution model is required by Slovenian legislation for industrial air pollution control because it is the most efficient for small domains over complex topography. To determine its performance and efficiency for regulatory purpose a research is made. In this research a general purpose modelling system designed for local scale areas is used. The main goal of the research is to define an enhanced statistical analysis used to evaluate an air pollution model of this kind where an operational configuration of both input data and model parameters are used and a testing period with very complex dispersion conditions is used. This enhanced evaluation can help to better understand the general quality that a model can achieve in these conditions. It gives some idea on how to better evaluate and use some results that seem to be very negative simply looking to some statistical parameter.
\end{abstract}

Keywords: air pollution, model evaluation, Lagrangian particle model, field data set.

\section{Introduction}

In accordance with the European Council Directive of 28 June 1984 on combating air pollution from industrial plants (84/360/EEC) a Slovenian Government decree on the emission of substances into the atmosphere from stationary sources of pollution came into force in April 2007. The decree defines that the performance of the air pollution model used to reconstruct air pollution 
around stationary sources must meet the requirements of complex terrain as defined in paper by Grašič et al. [1].

The Lagrangian-particle air pollution model is the one that fully satisfies all these requirements [2] among the currently available air pollution models. The main purpose of the research is an enhanced evaluation of the Lagrangianparticle air pollution model that is used for regulatory purposes over complex terrain. We are looking at its performances in severe conditions and trying to better understand and interpret some results.

\section{Enhanced evaluation method}

Standard method to evaluate the quality and performance of an air pollution model is based on statistical analysis of measured and reconstructed data. Measured data is obtained from automatic air quality measuring stations located around source of air pollution. Reconstructed data is obtained from simulation results performed with selected air pollution model. Evaluation is performed by statistical analysis of data that is available for selected time interval $T$. For the selected time interval a set of data patterns must be prepared where each data pattern consist of a pair of measured and reconstructed concentration $\{C m(t), \operatorname{Cr}(t)\}$.

During the evaluation following three performance indices are determined:

- the correlation coefficient:

$$
r=\frac{\frac{1}{T} \sum_{t=0}^{T}(C m(t)-\hat{C} m)(C r(t)-\hat{C} r)}{\sigma_{C m} \sigma_{C r}}
$$

- the normalized mean square error:

$$
N M S E=\frac{\frac{1}{T} \sum_{t=0}^{T}(C m(t)-C r(t))^{2}}{\hat{C} m \cdot \hat{C} r}
$$

- $\quad$ and the fractional bias:

$$
F B=2 \frac{\hat{C} m-\hat{C} r}{\hat{C} m+\hat{C} r}
$$

where

$\mathrm{Cm}(t)$...measured concentration at time $t$,

$\mathrm{Cr}(t)$...reconstructed concentration at time $t$,

$\hat{C} \quad$...average concentration,

$\sigma_{C} \quad$...concentration standard deviation,

$T \quad$...interval length (number of concentrations).

To avoid effect of model's inaccuracy of position and time of reconstructed concentrations an enhanced evaluation method is used. It is based on presented statistical analysis where additional reconstructed ground level concentrations around measuring station are used in comparison procedure as presented on 
Figure 1. In standard evaluation procedure only one reconstructed concentration is used from the cell where station is located $\operatorname{Cr}(t)=\operatorname{Cr}\left(t, m_{s}, n_{s}\right)$. In enhanced evaluation procedure a reconstructed concentration for comparison is selected from set of reconstructed concentrations $G C S(t)$ using best matching fuction $B M$. The function selects the reconstructed concentration that represents the best match according to measured concentration.
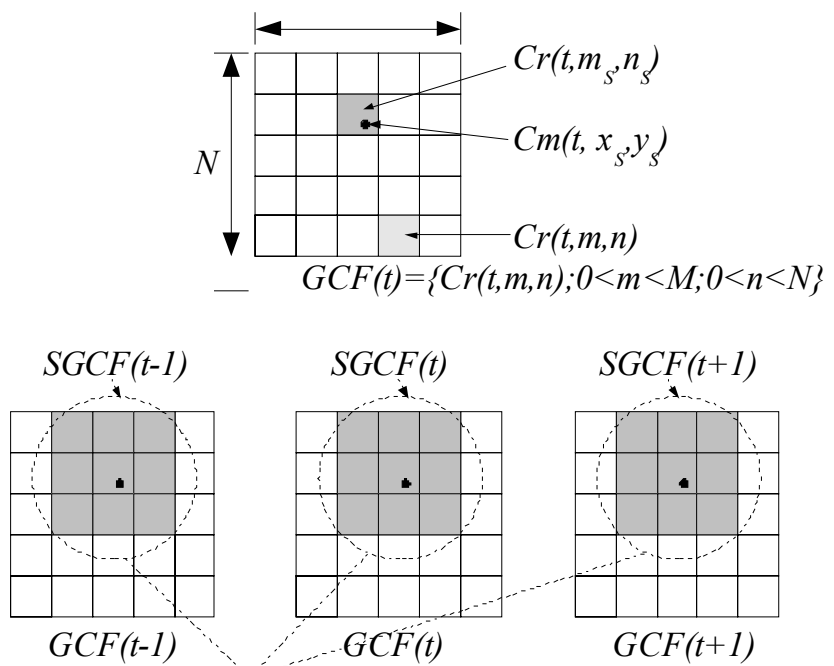

$$
\begin{aligned}
& G C S(t)=\{S G C F(t-1), S G C F(t), S G C F(t+1)\} \\
& C r(t)=B M(G C S(t))
\end{aligned}
$$

Figure 1: Determination of best matching reconstructed concentration within enhanced evaluation method where $x_{S}, y_{S}$ is the position of the station, $C m(t, x, y)$ is the measured concentration at position $(x, y)$, $m_{S}, n_{S}$ is the cell indexes at position of the station, $\operatorname{Cr}(t, m, n)$ is the reconstructed concentration at cell $(m, n), G C F(t)$ is the reconstructed ground concentration field at time $t, N$ is the number of cells in the east-west direction, $M$ is the number of cells in the north-south direction and $B M()$ is the best matching function.

\section{3 Šaleška region field data set}

For enhanced evaluation of the performance of the selected Lagrangian particledispersion model, data from a measuring campaign performed from $15^{\text {th }}$ of March to $5^{\text {th }}$ of April 1991 across the Šaleška region is used. The measuring campaign was performed as the joint effort of three institutions: ENEL-CRAM and CISE from Milano in Italy and the Jozef Stefan Institute from Ljubljana in 
Slovenia. The database from the measuring campaign was published and distributed on floppy disks in order to be available for further processing and research. The contents of the floppy disks are available as part of the final report [3].

In this measuring campaign the concentrations of $\mathrm{SO}_{2}$ higher than $1 \mathrm{mg} / \mathrm{m}^{3}$ were measured at surrounding stations. All of them were caused by the high emissions from the three stacks $(100 \mathrm{~m}, 150 \mathrm{~m}$ and $230 \mathrm{~m}$ high) of a thermal power plant that did not have desulphurization plants installed at that time. Because all other local sources of emission can be neglected, the data obtained during that measuring campaign can thus be used as a tracer experiment. The database was constructed from different measurement sources, like the Environmental Informational System (EIS) of the Šoštanj TPP, one mobile Doppler SODAR, DIAL and an automatic mobile laboratory.

The Šaleška region field data set is selected for several reasons:

- $\quad$ it spreads over complex orography (basin surrounded by high hills and a semi-mountainous continuation of the Karavanke Alps) where almost all possible complex terrain conditions occur,

- the database of ambient measurements is available from the measuring campaign organized in spring 1991,

- and the emissions from the three stacks of thermal power plant Šoštanj represent the main air-pollution source in the region.
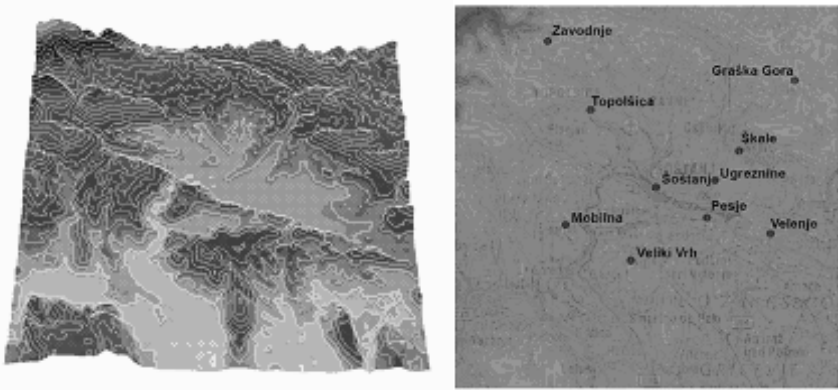

Figure 2: $\quad$ Šaleška region: complex topography of the valley and positions of automatic air quality and meteorological measuring stations.

\section{Results and discussion}

\subsection{Air pollution model and simulation}

The air pollution model is selected following the new Slovenian legislation: in complex terrain situation it is required to use a Lagrangian-particle air pollution model that is combined with corresponding meteorological pre-processor able to reconstruct a three dimensional diagnostic non-divergent wind field.

The Lagrangian-particle air pollution model termed SPRAY [4] is evaluated in this research. The exact description of selected air pollution model, parameters and options are given in the papers by Tinarelli et al. [4, 5]. Complex terrain 
situation is very common in Slovenia and almost all air pollution facilities are located at the bottom of basins, valleys or river canyons. The evaluation is needed because the Lagrangian-particle air pollution model evolved in the last ten years from research usage to usage for operational regulatory purposes $[5,6]$.

To describe particle velocity fluctuations and to generate $1 / 2$ hour average ground concentration field at the same horizontal resolution as used by meteorological reconstructions a Thomson's 1987 scheme with Gaussian random forcing [7] has been used. Emission from three stacks of the Šoštanj thermal power plant have been considered where each source of emission was described by static and dynamic parameters as presented in Table 1 . The plume rise undergone by hot stack plumes option has been simulated by means of the Anfossi's formulation [8].

Table 1: $\quad$ List of emission parameters.

\begin{tabular}{|l|l|l|l|l|l|l|}
\hline Stack & Position & Height & Diameter & Exit temperature & Exit velocity & Emission rate \\
\hline Stack 1 & $46,373 \mathrm{~N} 15,052 \mathrm{E}$ & $100 \mathrm{~m}$ & $6.50 \mathrm{~m}$ & $155 \div 171^{\circ} \mathrm{C}$ & $0.7 \div 2.9 \mathrm{~m} / \mathrm{s}$ & $0.01 \div 0.24 \mathrm{~kg} / \mathrm{s}$ \\
\hline Stack 2 & $46,372 \mathrm{~N} 15,053 \mathrm{E}$ & $150 \mathrm{~m}$ & $6.34 \mathrm{~m}$ & $155 \div 183^{\circ} \mathrm{C}$ & $8.8 \div 12.3 \mathrm{~m} / \mathrm{s}$ & $0.87 \div 2.05 \mathrm{~kg} / \mathrm{s}$ \\
\hline Stack 3 & $46,371 \mathrm{~N} 15,055 \mathrm{E}$ & $230 \mathrm{~m}$ & $6.20 \mathrm{~m}$ & $172 \div 202^{\circ} \mathrm{C}$ & $8.6 \div 12.7 \mathrm{~m} / \mathrm{s}$ & $0.53 \div 2.46 \mathrm{~kg} / \mathrm{s}$ \\
\hline
\end{tabular}

The simulation has been performed for the full duration of the campaign that lasted from $15^{\text {th }}$ of March until $5^{\text {th }}$ of April 1991. The result of simulation is a set of reconstructed air pollution episodes. Each air pollution episode represents average air pollution situation in time interval of $1 / 2$ hour described by a $3 \mathrm{D}$ concentration field, out of which only the 2D ground-level concentration field is relevant for the enhanced evaluation. 2D concentration field is described by a matrix of size 100x100 grid cells where each cell size is $150 \mathrm{~m}$ x $150 \mathrm{~m}$. The full size of domain is $15 \mathrm{~km} \mathrm{x} 15 \mathrm{~km}$ where the thermal power plant is located in the centre of domain as the source of emission.

\subsection{Standard evaluation results}

An evaluation is made at different directions around the thermal power plant where following four automatic air quality measuring stations are located: Graška Gora, Šoštanj, Veliki Vrh and Zavodnje. The measured and reconstructed $\mathrm{SO}_{2}$ concentrations at locations are presented on Figures 3, 4, 5 and 6 where a rotation of the air pollution plume from power plant over the domain is evident.

In higher layers at height from $200 \mathrm{~m}$ to $250 \mathrm{~m}$ wind changed its direction for north-west to south-east at the beginning of simulated period. The $\mathrm{SO}_{2}$ concentration on Graška Gora increased as a consequence of this change as presented in Figure 3. The figure also shows strong correlation of reconstructed $\mathrm{SO}_{2}$ concentrations with the measured ones. Later the wind changed its direction toward the south. This change caused an increase of $\mathrm{SO}_{2}$ concentrations at the Šoštanj and Veliki Vrh stations.

In Figure 4 the $\mathrm{SO}_{2}$ concentrations at the Šoštanj station are presented. The comparison shows that the reconstructed values are underestimated. The first reconstructed peak at 11:30 is underestimated mainly due to positional inaccuracy. While the second reconstructed peak is underestimated mainly due to 
the short distance between the station and the power plant which is approximately $500 \mathrm{~m}$. This short distance does not express strongly enough two effects: the stack tip down-wash effect and the effect of a low-wind speed directed towards the station in combination with convective turbulences.

The comparison of $\mathrm{SO}_{2}$ concentrations at the Veliki Vrh station presented on Figure 5 shows that two peaks of air pollution were reconstructed lasting from 00:00 to 04:00 and from 06:00 to 12:00. The reconstructed peaks are again a consequence of model's inaccuracy in the position. In the real situations such peaks with sharp edge could be created just few hundred metres from the station without being measured.

$\mathrm{SO}_{2}$ concentrations at the Zavodnje station are presented on Figure 6 where a similar process occurred. The phenomenon of inaccuracy in the position of the reconstructed peak is again very obvious. It caused the appearance of the first measured peak in the simulation that lasted from 00:00 to 04:00. The second measured peak at 13:30 was underestimated due to the phenomenon of air pollution accumulation [1] that was lost in the simulation due to the insufficient size of the area of interest.

Table 2 shows the results of statistical analysis resulting from a point-to-point comparison. Results appear to be quite dissatisfactory at a first view. Only the correlation at Graška Gora reaches a satisfactory value higher than 0.30 .

\subsection{Enhanced evaluation results}

Enhanced evaluation has been performed to avoid both effects of model's inaccuracy of position and time. Measured ground level concentration at

Table 2: $\quad$ Standard statistical comparison.

\begin{tabular}{|l|r|r|r|}
\hline \multicolumn{1}{|c|}{ Station } & \multicolumn{1}{c|}{ CORR } & \multicolumn{1}{c|}{ FB } & \multicolumn{1}{c|}{ NMSE } \\
\hline Graška Gora & 0,34 & 1,60 & 40,42 \\
\hline Šoštanj & 0,02 & 0,37 & 27,32 \\
\hline Veliki Vrh & 0,13 & 0,09 & 8,70 \\
\hline Zavodnje & $-0,004$ & 0,20 & 38,35 \\
\hline
\end{tabular}

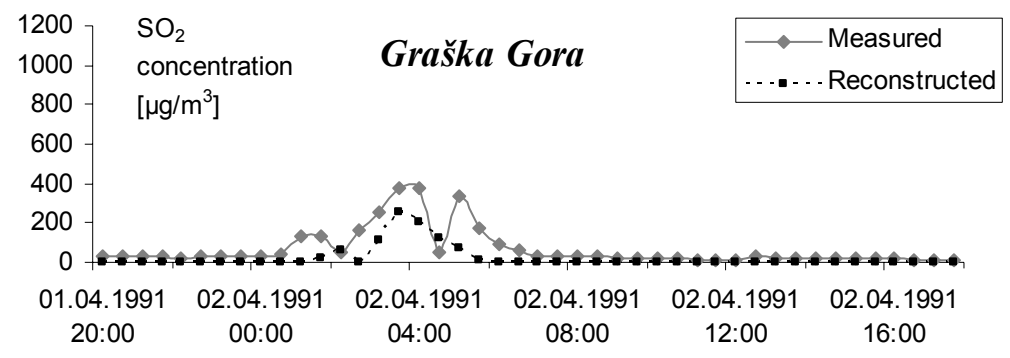

Figure 3: $\quad$ Standard comparison at Graška Gora. 


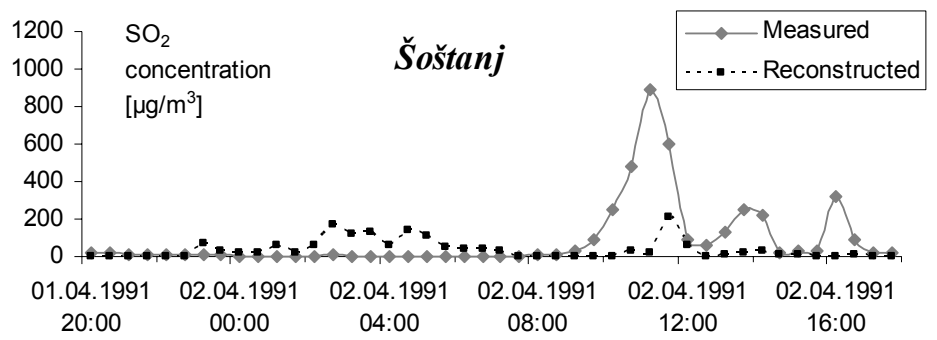

Figure 4: Standard comparison at Šoštanj.

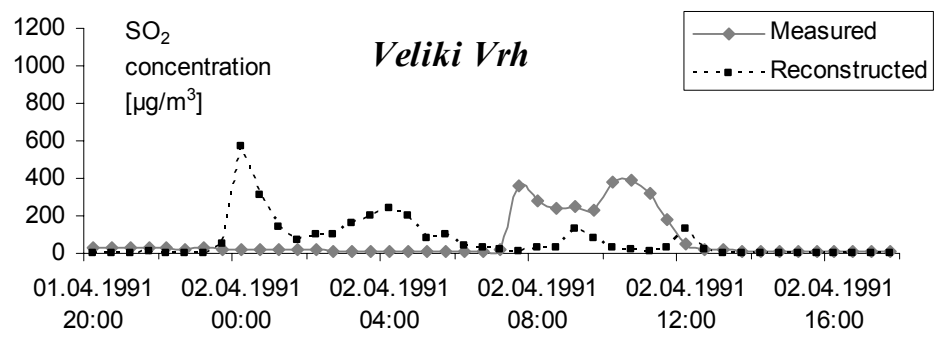

Figure 5: $\quad$ Standard comparison at Veliki vrh.

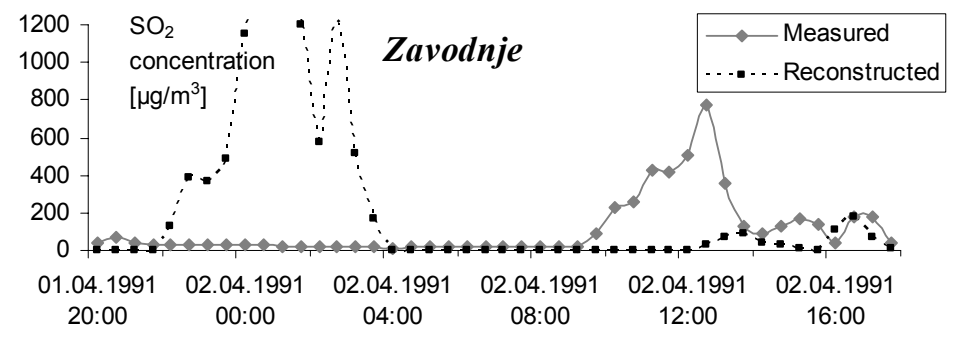

Figure 6: Standard comparison at Zavodnje.

locations of each four automatic station is compared to most similar reconstructed ground level concentration around the position of station in radius of $150 \mathrm{~m}$ and in time frame from $-1 / 2$ hour to $+1 / 2$ hour. The most similar reconstructed concentration for particular station is determined from the set of 27 combinations $(3 \times 3$ cells around position of the station combined with 3 time shifts for time reconstructions of $-1 / 2 \mathrm{~h}, 0 \mathrm{~h},+1 / 2 \mathrm{~h}$ ).

The results of enhanced evaluation are presented on Table 3. All correlations between measured and reconstructed values are significantly improved. Values of fractional bias are generally increased because several of overestimated reconstructed concentrations were reduced which also resulted in decrease of mean value of reconstructed concentrations. Fractional bias values generally 
increased because several of overestimated reconstructed concentrations are reduced. This also resulted in decrease of mean value of reconstructed concentrations.

Table 3: $\quad$ Enhanced evaluation results.

\begin{tabular}{|l|r|r|r|}
\hline \multicolumn{1}{|c|}{ Station } & CORR & \multicolumn{1}{c|}{ FB } & \multicolumn{1}{c|}{ NMSE } \\
\hline Graška Gora & 0,69 & 1,14 & 10,38 \\
\hline Šštanj & 0,36 & 0,95 & 20,64 \\
\hline Veliki Vrh & 0,74 & 0,61 & 3,26 \\
\hline Zavodnje & 0,37 & 0,79 & 6,30 \\
\hline
\end{tabular}

An enhanced evaluation is performed on the base of the comparison between measured and in time and space adjusted reconstructed $\mathrm{SO}_{2}$ concentrations. It is made at the positions of four automatic air quality measuring stations to compare the results with standard evaluation. The results of this comparison are presented on Figures 7, 8, 9 and 10 .

Figure 7 shows the $\mathrm{SO}_{2}$ concentration increase at Graška Gora that occurs at the beginning of the simulation. It also shows well agreement between the reconstructed and measured $\mathrm{SO}_{2}$ concentrations.

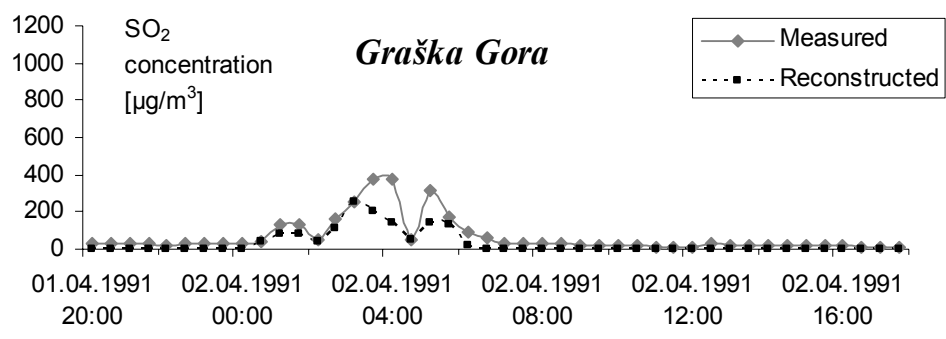

Figure 7: $\quad$ Enhanced comparison at Graška Gora.

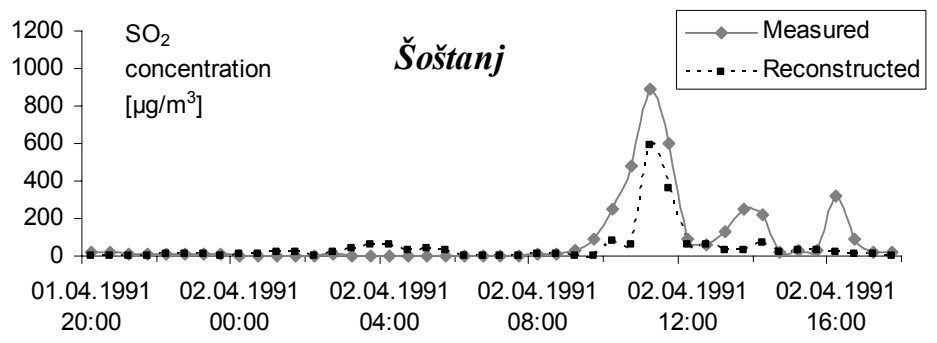

Figure 8: $\quad$ Enhanced comparison at Šoštanj.

In Figure $8 \mathrm{SO}_{2}$ concentrations at the Šoštanj station are depicted. It can be seen that the reconstructed values are now only slightly underestimated. 
$\mathrm{SO}_{2}$ concentrations at the Veliki Vrh station are depicted on Figure 9. Again the comparison shows two reconstructed peaks of air pollution that are very well correlated with measured ones.

At Zavodnje station comparison is presented on Figure 10. It is shown that the phenomenon of inaccuracy in the position of the reconstructed peak is strongly reduced. The lack of phenomenon of air pollution accumulation is still lacking.

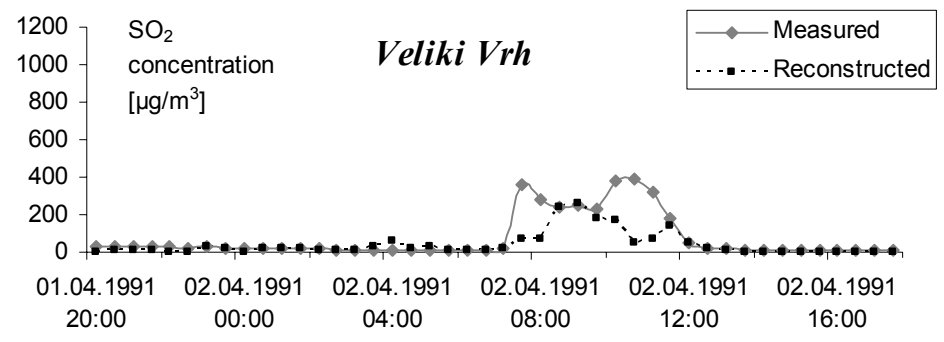

Figure 9: Enhanced comparison at Veliki vrh.

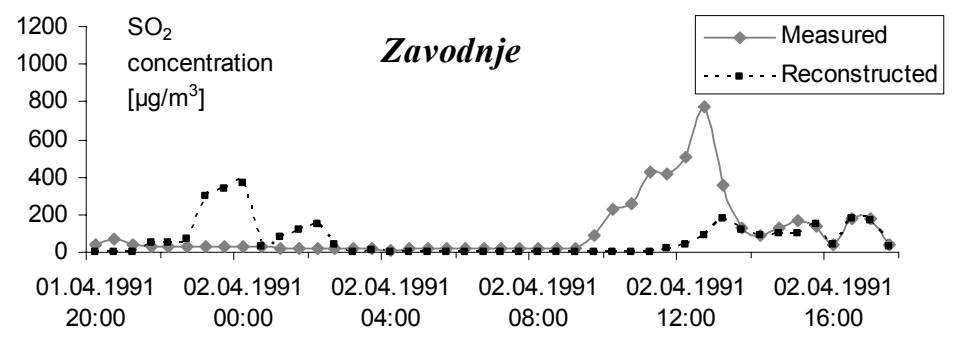

Figure 10: Enhanced comparison at Zavodnje.

\section{Conclusions}

Enhanced evaluation of the general purpose Lagrangian-particle air pollution model designed for local scale complex terrain has been made. Evaluation has been performed to determine the performance and efficiency of an air pollution modelling technique that is required by Slovenian legislation for industrial air pollution control.

Enhanced statistical analysis has been defined and performed to minimize the model's effect of inaccuracy of position and time. Measured ground level concentration at certain station measured have been compared to most similar reconstructed ground level concentration around the position of station in radius of $150 \mathrm{~m}$ and in time frame from $-1 / 2$ hour to $+1 / 2$ hour.

Significant improvement has been shown by this analysis. It pointed out the sensitivity of the model's to input parameters. Air pollution model is especially sensitive to measured wind speed and direction which could be improved in future. 


\section{Acknowledgement}

The authors gratefully acknowledge the contribution of the Ministry of Higher Education, Science and Technology of Republic of Slovenia, Grant No. 3211-05000552.

\section{References}

[1] Grašič B., Božnar M. Z., Mlakar P., Re-evaluation of the Lagrangian particle modelling system on an experimental campaign in complex terrain, Il Nuovo Cimento C, Vol. 30, No. 6, pp. 19-, 2007

[2] Wilson J. D., Sawford B. L., Review of Lagrangian stochastic models for trajectories in the turbulent atmosphere. Boundary-Layer Meteorology Vol. 78, pp. 191-210, 1996

[3] Elisei G., Bistacchi S., Bocchiola G., Brusasca G., Marcacci P., Marzorati A., Morselli M. G., Tinarelli G., Catenacci G., CORIO V., DAINO G., ERA A., Finardi S., Foggi G., Negri A., Piazza G., Villa R., Lesjak M., BOŽNAR M., Mlakar P., Slavic F.: Experimental campaign for the environmental impact evaluation of Sostanj thermal power plant, Progress Report, ENEL S.p.A, CRAM-Servizio Ambiente, Milano, Italy, C.I.S.E. Tecnologie Innovative S.p.A, Milano, Italy, Institute Jozef Stefan, Ljubljana, Slovenia, 1991

[4] Brusasca G., Tinarelli G., Anfossi D., Particle model simulation of diffusion in low windspeed stable conditions", Atmospheric Environment Vol. 26, pp. 707-723, 1992

[5] Tinarelli G., Anfossi D., Bider M., Ferrero E., Trini Casteli S., A new high performance version of Lagrangian particle dispersion model SPRAY, some case studies., Air pollution modelling and its Applications XIII, S. E. Gryning and E. Batchvarova eds., Kluwer Academic / Plenum Press, New York, pp. 499-507, 2000

[6] Graff A., The new German regulatory model - a Lagrangian particle dispersion model., 8th International Conference on Harmonisation within Atmospheric Dispersion Modelling for Regulatory Purposes, October 14-17, Sofia, Bulgaria, pp. 153-158, 2002

[7] Thomson D.J., Criteria for the selection of stochastic models of particle trajectories in turbulent flows, Journal of Fluid Mechanics, Vol. 180, pp. 529-556, 1987

[8] Anfossi D., Ferrero E., Brusasca G., Marzorati A., Tinarelli G., A simple way of computing buoyant plume rise in Lagrangian stochastic dispersion models, Atmospheric Environment Vol. 27A, pp. 1443-1451, 1993 